\title{
O MIGRANTE NORDESTINO EM BUSCA DO ELDORADO
}

\section{THE NORTHEASTERN MIGRANT IN SEARCH OF ELDORADO}

\section{RESUMO}

\author{
Edson Bastos Marinelli ${ }^{1}$
}

O presente trabalho traz como ponto central a discussão acerca das principais razões que dão sentido ao migrante nordestino, quando decide sair de suas terras e buscar melhores condições de vida. $\mathrm{O}$ artigo busca compreender se essa atração trará a solidificação de uma estrutura econômico/financeira, para aqueles que se propõem a conquistar vitórias e assim modificar uma situação presente na continuidade de sua história de vida. O contrário disso é renderse a ordem sistêmica em que ao seguir regras e determinações legais, pode contribuir com o recuo de sua decisão em permanecer em São Paulo retornando ao seu local de origem. Nessa construção e reconstrução da identidade, a psicologia procurará explicar as influências do processo de inclusão social bem como o movimento emancipatório que busca maior liberdade de ação e adaptação do indivíduo e grupos. Ao finalizar a leitura deixo aqui o convite ao leitor para fazer uma reflexão dos aspectos internalizados, contribuindo com sugestões e interesse no prosseguimento dos estudos, que levarão a outras descobertas em busca de soluções, para as questões inquietantes e ao mesmo tempo fascinantes quando discutimos o valoroso povo nordestino.

PALAVRAS-CHAVE: Migrante. Emancipação. Identidade Social. Metamorfose. Inclusão Social. Políticas Públicas

\section{ABSTRACT:}

The present work brings as central point discussion of the main reasons that give meaning to the Northeastern migrant, when he/she decides to leave their land and seek better living conditions. The article tries to understand if this attraction will bring the solidification of an economic/financial structure, to those that propose to win victories and so change a situation present in his/her life story continuity. The opposite of this is surrender to order on the following systemic rules and legal regulations, can contribute to the indentation of your decision to stay in São Paulo returning to his/her place of origin. In this construction and reconstruction of identity, psychology will seek to explain the influence of the process of social inclusion as well as the emancipating movement seeking greater freedom of action and adaptation of individual and groups. After reading here, I leave an invitation to the reader to make a reflection of internalized aspects, contributing suggestions and interest in the continuation of the studies, which will lead to other discoveries in the search for solutions to troubling issues and at the same time fascinating when we discussed the valiant people of northeastern Brazil.

KEYWORDS: Migrating. Emancipation. Social Identity. Metamorphosis. Social Inclusion. Public Policies

\footnotetext{
${ }_{1}$ Psicólogo, Mestre em Psicologia - Universidade São Marcos - 2007. Professor Psicologia - Universidade Guarulhos desde 1988. Consultor em Gestão de Pessoas. Autor dos Livros: Descubra Seus Talentos Humanos (2002); Comunicação Interpessoal: O Equilíbrio entre o Ouvir e Falar (2005)
} 
Acompanho, há mais de uma década, a saga da migração do povo nordestino para a região sudeste e as razões que os fazem decidir deixar suas terras e partir para outras por eles desconhecidas e inexploradas. O nordestino de nascimento carrega dentro de si o desejo de uma vida melhor para ele e àqueles a quem deve responsabilidades, mulher e filhos, como instituição formalmente constituída ou fruto de união mais fortuita, tendo como consequência uma nova constelação familiar.

O brasileiro divide suas raízes numa pluralidade extensa do solo nacional nos dias atuais, que se torna fácil observar pessoas nativas de diferentes estados espalhadas por todo nosso território.

Ainda hoje nota-se a pouca eficácia das políticas públicas para a região nordeste e isso favorece diretamente o êxodo, transformando em migrante o nativo expulsando-o de sua terra natal, mais propriamente do interior distante das capitais de seu estado.

Inicialmente a maioria procura fixar-se em cidades grandes e populosas do nordeste, seguindo seu caminho para as capitais e mais adiante dirigem-se para as regiões sul e principalmente sudeste por conta do clima mais tropical e aprazível, em busca de melhores oportunidades de emprego, já que despreparados profissionalmente, não escolhem um trabalho específico, a não ser que já venham com algum conhecimento e experiência que possam ser aproveitados, o que não corresponde à realidade da grande maioria.

O nordestino em sua terra tinha o domínio das técnicas do plantio e colheita do produto agrícola e era considerado "inteligente" e capaz de reorientar seu trabalho em função do tempo e época. Já em São Paulo, é uma pessoa muitas vezes considerada, em função do preconceito desenvolvido, como "ignorante" para funções mais bem remuneradas, submetendo-se a trabalhos como servente, faxineiro, ajudante geral e outros inúmeros cargos para os quais terá que obter novas competências.

Nessa questão, as manifestações da cultura nordestina que traz consigo, podem significar um possível movimento emancipatório por meio da arte, culinária, crenças e religião, diminuindo assim as grandes dificuldades de adaptação e o estigma que Ihes são objetivamente atribuídos e subjetivamente apropriados.
Para compreender este fenômeno e entender o sentido que o migrante nordestino atribui à sua permanência na capital paulista, torna-se imprescindível acompanhar dados demográficos e também as histórias por meio de narrativas, que podem ser considerados como uma construção de sentido realizada por ambos - pesquisador e participante.

O filho que decide sair de casa para conquistar o mundo, contra, muitas vezes, o desejo dos pais, que entendiam que estavam sendo abandonados à sua sorte, e que a desgraça recaia sobre a família; contudo, com o passar do tempo, isso foi se tornando normal e até desejado, pois se o filho alcançasse relativo sucesso, os demais membros poderiam vir em seguida. Ou o chefe de família que temporariamente deixa seu lar, mulher e filhos, partindo para o desconhecido com a promessa de voltar, ou ainda a família inteira que se entrega à sorte da peregrinação, são parte das histórias de vida de personagens que se tornam emblemáticos em sua determinação de vencer numa terra estranha, mas cheia de possibilidades e oportunidades.

Depois de se instalarem em pensões no centro da cidade ou bairros distantes, procuram se adaptar à nova vida, tentando um ganho que traga a sobrevivência necessária. Nisso, aqueles providos de alguma qualificação, mostram também a flexibilidade necessária para abrir mão de certos procedimentos culturais para poder dar o impulso em novas profissões.

Quanto à discriminação que sofrem, por serem nordestinos, esta é encarada de diferentes maneiras, desde sentimentos de desprezo, angústia, rancor ou um registro de reconhecimento e pela qual pode ser identificado, ou seja, se um alagoano, sergipano ou cearense é chamado de baiano, isso parece não importar, ao contrário, este "apelido", torna-se uma marca positiva numa cidade tão grande, um traço marcante que faz do nordestino uma pessoa emblemática.

Um passeio ao Museu do Ipiranga, para o nordestino, demonstra ter o mesmo sabor de descobrimento e regozijo que uma ida do visitante do Sudeste ao município de Poço Redondo - SE, na gruta de Angicos, onde Virgulino Lampião foi morto pela polícia em tocaia planejada. Este fato parece não merecer maior destaque no dia-a-dia do simples povo sertanejo. Mas lá estão sepultados Lampião, Maria Bonita e seu bando. Terra árida, vegetação retorcida e escassa da caa- 
tinga, e um sol escaldante a castigar.

Não se trata de adaptar uma psicologia para os pobres; ao contrário, torna-se imperativo gerar e difundir ações sociais capazes de acolher e incluir, ao invés de práticas de exclusão.

O nordestino quando aqui chega, se surpreende positivamente, pois, diferente de sua terra natal, encontra abundância de recursos para sua sobrevivência que beira o desperdício. Isso pode explicar o grande fluxo de pessoas que ano após ano chegam a São Paulo em busca de melhores condições de vida.

Alguns autores em contraposição referem-se a essa permanência, apoiando-se na crença que a intenção de muitos dos migrantes é ganhar dinheiro e retornar de onde veio, mas isso nem sempre ocorre devido a realidade que aqui encontram e os obriga a permanecer na cidade. Nessa perspectiva, entendem que o migrante não encontra um futuro melhor, mas a repetição obrigatória da miséria.

Pesquisas recentes do IPEA - Instituto de Pesquisa Econômica Aplicada (2016), sobre desigualdades e mudanças demográficas, aponta para a velocidade de retorno à terra de origem, que tem sido maior nos últimos anos, retornando rumo ao nordeste do que aquelas que aqui chegaram. Revela que aqueles que ficam preenchem vagas com salários baixos. A maioria ganha um salário mínimo, sendo um terço absorvido na construção civil. Outro dado peculiar verifica-se que os que voltam conseguem se empregar mais facilmente nas indústrias do que os residentes no Nordeste há mais de cinco anos, supondo-se que aqui eles se qualificam mais do que os que lá residem.

De acordo com estudos realizados na segunda metade da década de 1990 pelo CEM - Centro de Estudos Migratórios, com sede em São Paulo, uma das razões do êxodo para as grandes metrópoles foi a impossibilidade de sobrevivência no campo, pela falta de investimento na agricultura. Esta, cada vez mais voltada para as exportações, fez com que os pequenos produtores ficassem no abandono e engrossassem a fileira dos miseráveis, "boias-frias", diaristas e clandestinos. Souza (1980) entende o movimento migratório quando os grupos envolvidos no processo fixam residência em outro município diferente do de nascimento. Distingue a migração interna de outros tipos de deslocamentos como viagens comerciais, nomadis- mo, peregrinações, etc. A região sudeste foi o destino preferido da maioria daqueles que se deslocavam de outros estados brasileiros, sobretudo Minas Gerais e o Nordeste como um todo.

Observa-se, o que já foi dito sobre o deslocamento do sertanejo até aqui, que muitos fizeram a opção de deixar suas terras, sem que esta demonstrasse ser uma escolha planejada. Revela a fuga e a chance de sobrevivência, a possibilidade de um recomeço, de continuar a escrever sua história de vida. Sem os meios necessários para o sustento próprio e da família, o sertanejo quebra raízes, deixa seu passado e faz do presente uma porta para o futuro, conforme coloca Baptista (1998).

Patarra (1993) aponta que de um lado alguns especialistas veem com maior otimismo do que outros os passos dados em direção ao desenvolvimento econômico da região sul e sudeste; enquanto há aqueles que ressaltam o aspecto do prejuízo social e o atraso sofrido diante de um povo sem experiência profissional, pois vinham de uma atividade agrícola e perdiam muito tempo para se especializarem nas indústrias, comércio e serviços. Entende também que os movimentos representam a contrapartida das opções econômicas, mas que essa visão não pode ser imputada à população, pois ela é resultante de processos sociais específicos.

"Sou um sujeito pacato nordestino, acredito até mesmo no destino, posso até ser chamado sonhador". É o início de uma canção composta e interpretada por Flávio José (2003), um forrozeiro da Paraíba, um poeta do Nordeste. Todos temos sonhos, ambições, fantasias quanto ao futuro, nem sempre calcadas em metas bem estabelecidas, e por vezes com objetivos pouco definidos. A partir de um sonho nascem diferentes possibilidades e surgem oportunidades as quais se deve agarrar para que o momento não passe em branco. A indecisão, o medo do desconhecido, a estima rebaixada, a ignorância de saber como, a pouca motivação ou fraca determinação podem contribuir para o abandono da visão inicial da mudança.

"E assim vou vivendo a minha sina, sou um pobre de alma nordestina, obrigado a sair lá do sertão". Prossegue assim a canção. As razões que movimentam pessoas em busca de uma vida melhor, para si e os seus, levam a mudanças por vezes radicais, trazendo a incerteza dos resultados das atitudes e con- 
dutas, principalmente quando não houver o mínimo de planejamento. Daí o dilema do nordestino: ou fica em sua terra esperando ser reconhecido como agricultor ou assalariado ou sai do sertão carregando o saco de "coisas", usando como cadeado um nó e parte em busca do Eldorado. Quando quebra as amarras iniciadas por seus antepassados, inicia um movimento, com a intenção de se emancipar e, com isso, muda a si mesmo e novos referenciais passam a fazer parte de suas intenções quanto à busca de melhora de vida, mudando assim seus paradigmas pessoais.

A partir de depoimentos cedidos, Oliveira (1987) relata as principais dificuldades que os nordestinos tiveram para se fixar em São Paulo. Através de um modesto emprego, eles iniciavam a construção de suas casas, em mutirão, num terreno que financiavam em longo prazo, junto à periferia da cidade. Isso no passado, porque hoje as condições são piores que vinte anos atrás. Antigamente, o aluguel era trampolim para casa própria. Hoje devido as condições de vida e a falta de emprego, o aluguel deixa de ser a esperança de uma melhor moradia, para representar um peso demasiado grande a ser pago numa casa modesta, cuja tendência é a reversão para uma favela ou cortiço, devido ao empobrecimento do ser humano.

Isso fez com que bairros fossem se desenvolvendo e municípios sendo criados e, cada vez mais, o trabalhador se afastava do local de trabalho à procura de um lugar mais barato para morar. Com o crescimento urbano na periferia, novos empregos foram surgindo e fixando o homem em algumas regiões consagradas da cidade, destacando-se as zonas leste e sul, nos bairros de São Miguel Paulista e Santo Amaro respectivamente.

Baptista (1999) revela um espaço destinado exclusivamente ao público nordestino, se bem que é frequentado pelos paulistanos de uma forma geral. Falamos do C.T.N.- Centro de Tradições Nordestinas. Fundado em novembro de 1991, está situado no bairro do Limão, em uma área de 25 mil metros quadrados, proporcionando momentos de diversão, relacionamentos e resgate de valores entre seus frequentadores. O local oferece música ao vivo e comidas típicas em meio a um pátio e anexado à uma igreja, possui estátuas de personagens folclóricos e religiosos famosos, como Frei Damião e Padre Cícero, dentre outros.
É grande o número de pessoas que diariamente chegam a São Paulo, tendo como origem cidades dos estados do Nordeste. Entretanto, o sonho de uma vida melhor, que trazem ao chegar na grande metrópole, pode não se tornar realidade. Muitos insistem e não querem voltar com a sensação de derrota; outros preferem aceitar que aqui vivem melhor que lá, e há aqueles que acreditam que podem vencer e se preparam para isso.

Em minha experiência profissional, deparei-me com diferentes situações de migrantes nordestinos que, ao permanecerem em São Paulo, dois, três, dez anos, pensam um dia visitar seus parentes, mas não sabem quando e como. Visitar ou retornar em definitivo? Voltar como vitorioso ou fracassado? Aquele que está radicado há mais tempo, digamos mais de três anos, pode ou não ter conseguido uma situação econômico/financeira que lhe proporcione a opção de ir visitar os familiares. Caso não tenha juntado dinheiro suficiente, esteja trabalhando, mas sem as condições mínimas para viajar, pode, mesmo assim, preferir arriscar perder o emprego, somente para satisfazer seu desejo de rever seus entes. Sobre isso Weffort (1988, p. 22) diz: "para um imigrante pobre, viver só para trabalhar significa quase o mesmo que viver só para ser explorado".

Dados recentes revelam o processo inverso em relação à chegada de migrantes em São Paulo. De acordo com pesquisa do IPEA - Instituto de Pesquisa Econômica Aplicada (2006), mais nordestinos deixam São Paulo em relação aos que aqui chegam, o que não era comum até os anos 1990. Os números da pesquisa mostram que, nos últimos cinco anos, cerca de 457 mil pessoas retornaram para o nordeste contra cerca de 400 mil entradas. Revela ainda alguns dos motivos para essa "migração de retorno", entre eles a baixa escolaridade e o desemprego. Mesmo conseguindo colocar-se profissionalmente, normalmente o nordestino preenche vagas trabalhando por um salário baixo, seja em construção civil ou serviços domésticos. Destes, $67 \%$ ganham até um salário mínimo. Aqueles que retornam em sua maioria têm até 45 anos.

Assim, o deslocamento de pessoas para as grandes cidades, ao mesmo tempo em que trouxe progresso ao país, pode ter contribuído para o aumento de miséria para esses trabalhadores, visto que, ao partir de suas terras, o nordestino traz consigo a es- 
perança de melhores dias e, uma vez em São Paulo, sua missão de encontrar condições dignas de trabalho e de vida torna-se muito difícil. Aos poucos, o que se entende é que existe, naturalmente, um movimento de atração e outro de repulsão, visto que o elemento positivo e de possibilidades que existe nos grandes centros pode atrair o nordestino, mas talvez isso não seja o mais importante fator para o abandono da terra, já que como visto antes, o próprio estado de origem "expulsa" os seus, ou seja, um é consequência do outro.

O sujeito vai à busca de um sonho, algo possível de ser realizado e, através desse movimento que imagina ser emancipatório, ele pode mudar toda a história de sua vida e da família, num processo inconsciente de desconstrução e reconstrução da identidade.

As empresas culturalmente acostumadas a receber bem essas pessoas estão preparadas para encorajar a todos a continuar inovando e colaborando abertamente e podem inclusive constituir comissões de tutores que procuram compreender as dificuldades de adaptação através de contato com os funcionários, dirimindo e resolvendo eventuais dúvidas, propiciando momentos de reflexão nos tutelados sobre melhoria das relações existentes entre eles e a organização e demais partes envolvidas direta e indiretamente, ou seja, colegas, supervisão e direção.

Tais medidas servirão como incentivo ao migrante recém-chegado em sua adaptação, seja no trabalho em si como no convívio com os colegas e todo um contexto ambiental.

O migrante, ao encontrar seu espaço junto dos colegas de trabalho, a adaptação estará se solidificando e essas transformações em sua percepção poderão trazer um aumento progressivo de sua autoestima, mais conhecimento adquirido e a consequente segurança ao expor ideias em processos nos quais está envolvido, refletem-se na melhoria das relações sociais em diferentes situações fora do trabalho, com a família, amigos e, aos poucos, vai encontrando e delimitando um espaço social em que ele se sente aceito. Berger e Luckmann (2004), referindo-se ao agir social, ensinam que a vida cotidiana está repleta de múltiplos sucessos e que a identidade pessoal é formada nesse movimento.

Relativo a isso, Sennet (2000) coloca que o que falta ao trabalhador é a visão ampla sobre um futuro diferente, embora o presente imediato possa ser bastante claro quando um trabalhador maneja a mesma alavanca ou manivela horas a fio.

Dessa maneira, vejo que a realidade com que o migrante nordestino se depara fará parte de seu cotidiano e poderá levá-lo a outras conquistas de fundo emancipatório, assim que passe a compreender e considerar esse caminhar em busca de novas possibilidades pessoais e profissionais.

Mesmo assim esse maior equilíbrio não facilita a vida do migrante nordestino em São Paulo, visto que quanto mais competências ele, e outros não migrantes, passam a ter, aumentam os níveis de exigências das empresas, bem como a possibilidade de não haver poder de negociação salarial por parte dos candidatos na hora da admissão.

Portanto, salário não parece ser um fator determinante na melhoria de vida dos brasileiros já há bastante tempo. No passado, Marx, com seu esforço socialista de liberdade e igualdade procurou equilibrar a balança do poder em favor do proletariado, empenhando-se numa luta cujas armas foram suas palavras e as publicações de seus escritos e livros, sendo por isso perseguido e expulso de países durante grande parte de sua vida, sem, porém, desistir de seus ideais. Trouxe ainda grandes contribuições para a formação moral da sociedade. Acerca de sua visão sobre o trabalho e as relações empregado e empregador, Marx (1985) afirma:

O trabalho não é senão o uso da força de trabalho cujo conteúdo consiste nas aptidões físicas e intelectuais do operário. Sendo assim, o salário recebido não paga o valor do trabalho, mas o valor da força de trabalho, cujo uso, no processo produtivo, cria um valor maior do que o contido no salário. O valor de uso da força de trabalho consiste precisamente na capacidade, que the é exclusiva, de criar um valor de grandeza superior à sua própria. $\mathrm{O}$ dono do capital e empregador do operário se apropria deste sobrevalor ou mais-valia sem retribuição (MARX, 1985, p. 213).

Rattner (2004) defende a geração de empregos com vistas à inclusão social. Afirma que, ao longo das 
últimas décadas, a produtividade do trabalho dos brasileiros tem aumentado significativamente, porém esse fator não gerou como consequência elevação correspondente nos salários, que, ao contrário, encolheu, conforme dados do IBGE, SEADE e IPEA.

Essa metamorfose constante na busca de uma pretensa emancipação não completa o ciclo, visto que outros objetivos surgirão e novos movimentos emancipatórios emergirão nas histórias de vida das pessoas.

As experiências adquiridas vão criando sentidos para o indivíduo, sendo por ele apropriadas, incorporadas, reafirmando sua identidade de forma singular, obtendo o reconhecimento social na interação com o meio em que vive. Nessa rede de relacionamentos interpessoais o indivíduo é exposto para o outro na medida de seu envolvimento e isso pode moldar sua atual identidade. Com o tempo, essa identidade tende a se reformular através de um processo de individualização, criando uma maior independência dos sistemas sociais, conquistando mais liberdade em seu espaço de vida.

Para Berger e Luckmann (1985), a identidade é formada por processos sociais, que, quando cristalizada, é mantida, modificada e até remodelada pelas relações sociais e trata-se de um fenômeno derivado da dialética entre o indivíduo e a sociedade, em que o homem produz a realidade e com isso se produz a si mesmo.

Quando nos referimos à identidade coletiva desejamos focalizar o grupo representativo no qual o nordestino está inserido, objeto de nosso estudo, descartando a população como um todo.

Tanto a identidade individual como a coletiva são, portanto, construções do homem considerado como produto social de sua interação com seu meio, o qual busca, através de metamorfoses, sua emancipação. A decisão individual uma vez tomada resultará em uma ação também individual, mas que irá ao mesmo tempo fazer parte de um processo dinâmico em que a experiência vivida se constituirá socialmente, ou seja, as escolhas pessoais influem e modificam o meio social.

Vivemos nos dias atuais numa sociedade plural, onde é difícil fazer previsões futuras, e um tempo em que as mudanças ocorrem com muita rapidez e cabe ao ser humano se adaptar a elas. Se no passado era mais fácil planejar a vida, fazer uma carreira, saber com quem casar, hoje, por outro lado, existem maiores opções de escolhas em todos os campos e paradoxalmente as pessoas podem se sentir confusas e perdidas justamente pela diversidade de possibilidades.

Em outras palavras, o mundo da vida que leva em conta a tradição, os usos e costumes de um povo, dando-lhe um sentido na busca de soluções de problemas e o surgimento de novas ideias, cede cada vez mais espaços para uma ordem sistêmica, a qual exige um controle severo sobre as pessoas, interferindo através de estratégias e imposições junto à sociedade e buscando sua rápida adaptação aos modelos econômicos vigentes, sistemas de governo, competências profissionais e tecnologia.

A história da migração atravessou esse período, de uma era de certezas e maior conformismo para a atual. Ousamos dizer que o perfil do migrante foi sendo modificado e hoje ele chega a São Paulo com muito mais informações que antes, porém as dificuldades são até maiores diante da escassez de oportunidades ofertadas e adequadas às suas qualificações.

Pode-se entender também como a identidade da pessoa vem a se transformar, a partir de sucessivos acontecimentos que podem levar o migrante nordestino a refazer seus caminhos, fazendo-o refletir sobre um possível recuo em suas intenções para posterior avanço mais vigoroso ou abandonar de vez a ideia inicial. Essa intenção motivada por um desejo e sua não realização pode por vezes causar frustração ou levar a conflitos internos, e relativo a isso Habermas (1976) considera:

Tais conflitos podem surgir da perda imprevista de ligações de inserção social, assim como do ingresso inesperado em novas posições e esferas existenciais, como o desemprego, a emigração, a guerra, a ascensão social, ou por catástrofes privadas plenas de consequências. Em certas circunstâncias, tais conflitos constituem uma carga tão forte para a personalidade que essa se encontra diante da alternativa de se quebrar ou de iniciar uma nova vida (HABERMAS, 1976, p. 78).

A história da migração é rica em detalhes daqueles migrantes que, por diferentes motivos, oriundos 
de lugares distantes, dentro e fora do Brasil, ajudaram a povoar nosso estado e que contribuíram decisivamente com seu suor para o engrandecimento local, deixando muitas vezes de receber a devida gratidão ou o reconhecimento social.

Todo esse movimento migratório parece ter sido marcado por histórias de sacrifícios, sendo que para o nordestino decidir deixar sua família e vir inicialmente sozinho, tinha que optar por essa possibilidade de ficar sem ver seus entes durante um tempo que não tinha como dimensionar, buscando criar novas possibilidades de sobrevivência para si e para a família, mudando seus referenciais, na busca de sua emancipação.

Portanto, se de um lado o êxodo rural dos nordestinos representou uma abundância de trabalhadores baratos nas indústrias do Sudeste e com isso o crescimento desordenado da população sem a infraestrutura básica, como habitação, saneamento e educação, favorecendo o crescimento das favelas; de outro aponta para uma realidade em que a exploração voraz capitalista ainda precisa do migrante como força de trabalho disponível. Por isso, esse povo sofrido merece o devido destaque e ser reconhecido e valorizado.

\section{REFERÊNCIAS}

BAPTISTA, Dulce Maria Tourinho. Nas terras do "Deus-Dará": nordestinos e suas redes sociais em São Paulo. 1998. 238 f. Tese (Doutorado em Ciências Sociais) - Faculdade de Ciências Sociais, Pontifícia Universidade Católica, São Paulo, 1998.

BAPTISTA, Dulce Maria Tourinho. CTN: um nordeste paulistano. Travessia - Revista do Migrante. São Paulo: Centro de Estudos Migratórios, ano XII, $n^{\circ} 34$, p. 39-42, maio-agosto 1999.

BERGER, Peter L.; LUCKMANN, Thomas. A construção social da realidade. Petrópolis: Vozes, 1985.

CEM - Centro de Estudos Migratórios de São Paulo. 0 vaivém da sobrevivência. São Paulo: Edições Paulinas, 1993.

HABERMAS, Jurgen. Para a reconstrução do materialismo histórico. São Paulo: Brasiliense, 1976.

IPEA - Instituto de pesquisa econômica aplicada. Desigualdades, mudanças demográficas recentes e perfil epidemiológico como variáveis políticas de saúde - uma análise regional - 2006. Disponível em: http://www.ipea.gov.br/brasil:radiografiadasaúde/campinas/unicamp/2006

JOSÉ, Flávio. Cidadão comum. LBC - CD. 101.313, 2003.

MARX, Karl. O Capital: crítica da economia política. São Paulo: Nova Cultural, 1985.

OLIVEIRA, Antonio Alves. Os nordestinos em São Paulo: depoimentos. São Paulo: Edições Paulinas, 1987.

PATARRA, Neide L. Movimentos migratórios: características e tendências recentes. São Paulo: Edições Paulinas, 1993.

RATTNNER, Henrique. Em busca do crescimento econômico - cronicamente inviável. Revista Espaço Acadêmico, São Paulo, n 32, p. 2-3, abril 2004.

SENNETT, Richard. A corrosão do caráter: Consequências pessoais do trabalho no novo capitalismo. Rio de Janeiro: Record, 2000.

SOUZA, Itamar de. Migrações internas no Brasil. Petrópolis: Vozes, 1980.

WEFFORT, Francisco Correa. Nordestinos em São Paulo. São Paulo: Cortez, 1988. 